\title{
Lung deposition of a radiolabeled aerosol with two ventilation modalities during invasive mechanical ventilation: a randomized comparative study
}

\author{
J Dugernier ${ }^{*}$, G Reychler ${ }^{2}$, X Wittebole ${ }^{1}$, J Roeseler ${ }^{1}$, T Sottiaux $^{3}$, JB Michotte $^{4}$, R Vanbever $^{5}$, T Dugernier $^{6}$,

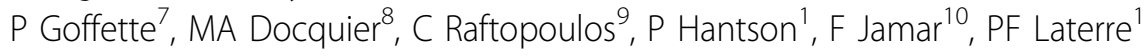

From ESICM LIVES 2015

Berlin, Germany. 3-7 October 2015

\section{Introduction}

Volume-controlled ventilation has been suggested during nebulization to optimize lung deposition although promoting spontaneous ventilation is targeted for ventilated patient management. Comparing topographic lung aerosol deposition during volume-controlled and spontaneous ventilation in pressure support has never been performed.

\section{Objectives}

The aim of this study was to compare lung deposition of a radiolabeled aerosol generated with a vibrating-mesh nebulizer during invasive mechanical ventilation, using two ventilation modes: pressure support ventilation (PS) and volume-controlled ventilation (VC).

\section{Methods}

Seventeen postoperative neurosurgical patients without pulmonary disease volunteered to participate in the study and were randomly ventilated in PS $(\mathrm{n}=8)$ or VC $(\mathrm{n}=9)$ with constant inspiratory flow. Diethylenetriaminepentaacetic acid labelled with technetium-99 m $(2 \mathrm{mCi} / 3 \mathrm{~mL})$ was administered using a vibrating-mesh nebulizer (Aerogen Solo ${ }^{\circledR}$, Aerogen Ltd., Galway, Ireland) connected to the endotracheal tube. Pulmonary and extrapulmonary particles deposition was analyzed by planar scintigraphy.

\section{Results}

Mean lung deposition expressed as a percent of nominal dose was $10.5 \pm 3.0 \%$ and $15.1 \pm 5.0 \%$ during PS and $\mathrm{VC}$, respectively $(\mathrm{p}<0.05)$. Higher endotracheal tube and tracheal deposition was observed during PS $(27.4 \pm 6.6 \%$ versus $20.7 \pm 6.0 \%, \mathrm{p}<0.05)$. A similar aerosol penetration from the inner to the outer region of the right lung $(\mathrm{p}=0.347)$ and the left lung $(\mathrm{p}=0.239)$ was observed.

\section{Conclusions}

Volume-controlled ventilation improved lung deposition of aerosolized particles as compared to pressure support ventilation. The clinical benefit of this effect warrants further studies.

\begin{abstract}
Authors' details
'Université Catholique de Louvain, Cliniques Universitaires Saint Luc, Intensive Care Unit, Brussels, Belgium. ${ }^{2}$ Université Catholique de Louvain, Institut de Recherche Expérimentale et Clinique (IREC), Pneumology, Brussels, Belgium. ${ }^{3}$ Clinique Notre-Dame de Grâce, Intensive Care Unit, Gosselies, Belgium. ${ }^{4}$ Haute Ecole de Santé Vaud, Lausanne, Switzerland. ${ }^{5}$ Université Catholique de Louvain, Cliniques Universitaires Saint Luc, Louvain Drug Research Institute, Brussels, Belgium. ${ }^{6}$ Clinique Saint-Pierre, Intensive Care Unit, Ottignies, Belgium. 'Université Catholique de Louvain, Cliniques Universitaires Saint Luc, Department of Interventional Radiology, Brussels, Belgium. ${ }^{8}$ Université Catholique de Louvain, Cliniques Universitaires Saint Luc, Department of Anesthesiology, Brussels, Belgium. '9niversité Catholique de Louvain, Cliniques Universitaires Saint Luc, Department of Neurosurgery, Brussels, Belgium. ${ }^{10}$ Université Catholique de Louvain, Cliniques Universitaires Saint Luc, Department of Nuclear Medicine, Brussels, Belgium.
\end{abstract}

Published: 1 October 2015

doi:10.1186/2197-425X-3-S1-A10

Cite this article as: Dugernier et al:: Lung deposition of a radiolabeled aerosol with two ventilation modalities during invasive mechanical ventilation: a randomized comparative study. Intensive Care Medicine Experimental 2015 3(Suppl 1):A10.

'Université Catholique de Louvain, Cliniques Universitaires Saint Luc, Intensive Care Unit, Brussels, Belgium

Full list of author information is available at the end of the article

(C) 2015 Dugernier et al.; This is an Open Access article distributed under the terms of the Creative Commons Attribution License (http://creativecommons.org/licenses/by/4.0), which permits unrestricted use, distribution, and reproduction in any medium, provided the original work is properly cited. 